\title{
Prevalence of Staphylococcus aureus colonization in renal transplant patients*
}

\author{
PREVALÊNCIA DE COLONIZAÇÃO POR STAPHYLOCOCCUS AUREUS EM PACIENTES \\ TRANSPLANTADOS RENAIS
}

\section{PREVALENCIA DE COLONIZACIÓN POR STAPHYLOCOCCUS AUREUS EN PACIENTES TRANSPLANTADOS RENALES}

\author{
Luiz Carlos Ribeiro Lamblet ${ }^{1}$, Dulce Aparecida Barbosa²
}

\begin{abstract}
Objective: to evaluate the prevalence of Staphylococcus aureus nasal colonization in renal transplant patients and to identify the related risk factors. Method: Swabs were used to collect nasal samples from 160 patients who had undergone a transplant within the previous year at the Kidney and Hypertension Hospital. The 'National Committee for Clinical Laboratory Standards' norms were followed for the collection, isolation, identification and sensitivity measurements. Results: There was a $9.4 \%$ (15) prevalence of Staphylococcus aureus nasal colonization, of which one $(6.7 \%)$ was resistant to oxacillin. It was possible to identify as an associated risk factor a wait of more than one year for accessing dialysis prior to the transplant $(p=0.029)$. Conclusion: Given the high morbidity and mortality rates that this microorganism causes in the target population, other studies should be carried out, and pre- and post-transplant screening should occur in order to develop strategies that improve the prevention and control of the spread of Staphylococcus aureus.
\end{abstract}

\section{DESCRIPTORS}

Kidney transplantation

Staphylococcus aureus

Methicillin resistance

Infection control

\section{RESUMO}

Objetivo: Avaliar a prevalência da colonização nasal por Staphylococcus aureus em pacientes transplantados renais e identificar os fatores de risco relacionados. Método: Foram coletadas amostras nasais por meio de swabs de 160 pacientes com até um ano de transplante realizado no Hospital do Rim e Hipertensão. A coleta, isolamento, identificação e o perfil de sensibilidade foram realizados segundo as normas do National Committee for Clinical Laboratory Standards. Resultados: A prevalência de colonização nasal por Staphylococcus aureus foi de 9,4\% (15), sendo um resistente à oxacilina $(6,7 \%)$. Foi possível identificar como fator de risco associado o tempo de acesso para diálise maior que um ano $(p=0,029)$ prévio ao transplante. Conclusão: Devido à elevada morbidade e mortalidade causada por esse microrganismo nessa população, faz-se necessária a realização de outros estudos, adotando o screening nos períodos pré e pós-transplante para definir estratégias de prevenção e controle da disseminação do Staphylococcus aureus.

\section{DESCRITORES \\ Transplante de rim Staphylococcus aureus Resistência a meticilina Controle de infecções}

\section{RESUMEN}

Objetivo: Evaluar la prevalencia de la colonización nasal por Staphylococcus aureus en pacientes transplantados renales e identificar los factores de riesgo relacionados. Método: Fueron recogidas muestras nasales por medio de swabs de 160 pacientes con hasta un año de hecho el transplante en el Hospital del Riñón e Hipertensión. La recolección, el aislamiento, la identificación y el perfil de sensibilidad fueron llevados a cabo según las normas del National Committee for Clinical Laboratory Standards. Resultados: La prevalencia de colonización nasal por Staphylococcus aureus fue del 9,4\% (15), siendo uno resistente a la oxacilina $(6,7 \%)$. Fue posible identificar como factor de riesgo asociado el tiempo de acceso para diálisis mayor de un año $(p=0,029)$ previo al transplante. Conclusión: En virtud de la elevada morbilidad y mortalidad causada por ese microrganismo en dicha población, se hace necesaria la realización de otros estudios, adoptándose el screening en los períodos pre y post transplante a fin de definir las estrategias de prevención y el control de la diseminación del Staphylococcus aureus.

\section{DESCRIPTORES \\ Transplante de rinón Staphylococcus aureus Resistencia a la meticilina Control de infecciones}

\footnotetext{
* Extracted from the dissertation "Avaliação da prevalência de colonização por Staphylococcus aureus em pacientes transplantados renais", Universidade Federal de São Paulo, 2008. ${ }^{1}$ Master of Health Sciences, Universidade Federal de São Paulo, São Paulo, SP, Brazil. ${ }^{2}$ Associated Professor at, Escola Paulista de Enfermagem, Universidade Federal de São Paulo, São Paulo, SP, Brazil.
}

$\begin{aligned} \text { Rev Esc Enferm USP } & \text { Received: } 01 / 22 / 2014 \\ \text { 2014; 48(5):824-30 } & \text { Approved: 07/14/2014 }\end{aligned}$




\section{INTRODUCTION}

Hospital-acquired Staphylococcus aureus (S.aureus) infections result in 292 thousand hospitalizations and 19 thousand deaths per year ${ }^{(1-2)}$. In the USA, $28.6 \%$ of the population are thought to be infected and $1.5 \%$ to be oxacillin resistant $(\mathrm{ORSA})^{(3)}$. In patients with end stage renal disease (ESRD), S.aureus infection is the greatest cause of morbidity and the second most significant cause of death, after cerebrovascular events ${ }^{(4)}$. Colonization of the nasal passage and of the catheter insertion site in the population of dialysis patients is associated with the presence of infection ${ }^{(4-5)}$, with an increase in infections of the blood stream and the need for surveillance and control measures ${ }^{(6-7)}$. In Brazil, 11,436 renal transplants were carried out between 2007 and 2009, of which 4,632 (40.5\%) occurred in Sao Paulo state. Of these, $2,170(46.8 \%)$ took place at the Kidney and Hypertension Hospital (HRim) and at the Federal University of Sao Paulo, UNIFESP(8). The increase in the number of kidney transplant patients is a challenge, since survival rates are continually improving, patients are older and there is a greater number of comorbidities. As a result, there is a need for more regular monitoring and there has been a rise in the number of hospitalizations for treatment meaning an increase in prior contact with microorganisms such as S.aureus and other agents of hospital infection. Studies of the colonization and infection of S.aureus have been carried out on dialysis patients, and have shown an increased prevalence of the agent and a direct relationship with cases of endocarditis ${ }^{(9-10)}$. Recently, molecular typing has served to show that cross infection by multiresistant microorganisms occurs in dialysis and renal transplant patients that were monitored during treatment ${ }^{(11)}$. Another important element is that patients who undergo renal transplants are particularly susceptible to colonization not only arising from dialysis, but also because they experience greater immunosuppression, particularly in the first year after receiving the transplant ${ }^{(12)}$. Data is not available regarding S.aureus colonization in kidney transplant receptors, therefore this study could help to establish an endemic level of colonization of this agent in renal graft receptors, and to support actions aimed at preventing and controlling the spread of this microorganism. Given this context, the objectives of this study were to evaluate the prevalence of S.aureus nasal colonization in renal transplant patients and to identify the related risk factors for patients infected by S.aureus.

\section{METHODS}

Ethical considerations: The study received approval (number 592/04) from the Research Ethics Committee at the Federal University of Sao Paulo, UNIFESP and involved the signing of clear and free consent forms.
Design, period and location of the study: This transversal study took place between March 2009 and December 2011 at the HRim university hospital at UNIFESP, which is considered to an institution of international excellence which is responsible for around 900 to 1,000 transplants per year.

Population and sample: On the basis of an estimated $30 \%$ prevalence of $\mathrm{S}$.aureus colonization in a healthy population and an error estimate of around 7\%, considering a type I error of $5 \%$ and a type II error of $20 \%$ in the effected population, 160 patients were included in the study. For the prevalence analysis the study sample was made up of patients over the age of 18, and divided up according to the immunosuppression protocols adopted: 60 patients with up to 30 days of transplant (loading dose), 50 patients with between two and six months (adequacy dose) and 50 patients with between six months and a year (maintenance dose). The patients who had most recently undergone transplant were evaluated within the hospital soon after the transplant, while the other groups were made up of patients that were chosen at random from outpatient facilities for renal transplant at UNIFESP. Those patients that did not give their consent to participate in the study were excluded.

Study protocol: A registry was prepared containing data that enabled clinical identification: sex, age, race, primary renal illness, type of dialysis and time and dialysis access prior to the transplant, human leukocyte antigen (HLA) pairing, blood transfusions prior to the transplant and type of immunosuppressive treatment. From the medical records, information was collected regarding the result of the microbiological analysis and relevant infection during the period post-transplant.

Laboratory Methodology: A single nasal sample was collected from one nostril of each of the 160 patients. Nasal collection was chosen given the direct relationship between the nasal carrier and the risk of infection by the agent. Alginate swabs that had been dampened with sterile lactated Ringer's solution were used for the collection of the nasal sample. The swab was introduced to the lower region of the nostril and delicately twisted. Once the collection had been carried out, the swab was soaked in $\mathrm{BHI}$ solution (tubes containing $2.5 \mathrm{ml}$ of Brain Heart Infusion - BHI, Difco). After incubating at $350 \mathrm{oC}$ for 18 to 24 hours, the samples in the $\mathrm{BHI}$ solution were cultivated in agar blood containers (Columbia Blood Agar, Difco, enriched with $5 \%$ sheep's blood) with or without oxacillin, and Mannitol salt agar (Difco). After 24 hours, the containers were examined to check for growth of the bacterial colonies and were identified using classical biochemical tests ${ }^{(13)}$. The tests for isolated strains to determine resistance to oxacillin were carried out using the disk diffusion method, following the norms established by the National Committee for Clinical Laboratory Standards (NCCLS) ${ }^{(14)}$. The laboratory procedures were performed in the Special Clinical Microbiology Laboratory at UNIFESP. 
Statistical analysis and results: For the analysis of results, the patients were considered as being colonized or not by the S.aureus. The analysis of results with regard to the time since transplant was carried out for those patients who were infected by the microorganism. The method included a descriptive analysis, taking into account clinical and laboratory variables and parameters related to the transplant. A bivariate analysis followed in which the groups (infected or not) were compared. For continual variables, Student's ttest or the Mann-Whitney test were applied, when appropriate. Categorical variables were tested using the chi square of Fisher's exact test. The tests that were applied were two tailed, and the significance level used was $p<0.05^{(15)}$.

\section{RESULTS}

Demographic data relating to patients with and without S.aureus are presented in Table 1, along with the clinical characteristics prior to the renal transplant.

Table 1 - Demographic and clinical characteristics prior to the transplant of renal receptors, Sao Paulo, 2011

\begin{tabular}{|c|c|c|c|c|c|}
\hline \multirow{2}{*}{ Characteristics } & \multicolumn{2}{|c|}{ Staphylococcus aureus } & \multicolumn{2}{|c|}{ Negative } & \multirow[b]{2}{*}{$p$} \\
\hline & $\mathrm{n}=15$ & $\%$ & $n=145$ & $\%$ & \\
\hline \multicolumn{6}{|l|}{ Sex } \\
\hline Masculine & 11 & 73.3 & 91 & 62.8 & \multirow[t]{2}{*}{0.417} \\
\hline Feminine & 4 & 26.7 & 54 & 37.2 & \\
\hline Age $X \pm$ DP & $41.3 \pm 11.9$ & & $41.7 \pm 10.8$ & & 0.904 \\
\hline \multicolumn{6}{|l|}{ Ethnicity } \\
\hline White & 10 & 66.7 & 88 & 60.7 & \multirow[t]{2}{*}{0.651} \\
\hline Non White & 5 & 33.3 & 57 & 39.3 & \\
\hline \multicolumn{6}{|c|}{ Treatment prior to transplant } \\
\hline Hemodialysis & 15 & 100.0 & 125 & 86.2 & \multirow{3}{*}{0.307} \\
\hline Peritoneal dialysis & & & 13 & 9.0 & \\
\hline Conservative care & & & 7 & 4.8 & \\
\hline \multicolumn{6}{|l|}{ Time since access } \\
\hline$>1$ year & 14 & 93.3 & 89 & 61.4 & \multirow[t]{2}{*}{0.029} \\
\hline$<1$ year & 1 & 6.7 & 56 & 38.6 & \\
\hline Blood transfusions & 3 & 20.0 & 14 & 9.7 & 0.202 \\
\hline \multicolumn{6}{|l|}{ Primary renal illness } \\
\hline Indeterminate & 8 & 53.3 & 28 & 19.3 & \multirow{4}{*}{0.028} \\
\hline Hypertension & 2 & 13.3 & 36 & 24.8 & \\
\hline Glomerulonephritis & 2 & 13.3 & 22 & 15.2 & \\
\hline Other & 3 & 20.0 & 59 & 40.7 & \\
\hline
\end{tabular}

Among the colonized patients, 11 (73.3\%) were male and $10(66.7 \%)$ were white. All had carried out hemodialysis prior to the transplant, and $93.3 \%$ had made their first venal access at least a year previously. Of these, $13(86.7 \%)$ carried out the dialysis through an arteriovenous fistula and two (13.3\%) using a central venous catheter. Among the colonized patients, eight (53.3\%) had undetermined primary renal illness. There was a statistically significant association between access time of a year or more in dialysis $(p=0.02)$ and undetermined primary renal illness $(p=002)$ with nasal colonization by S.aureus. At the center where the study was carried out, an antimicrobial prophylaxis is carried out on $100 \%$ of transplant patients. Cefalexin (cephalosporin) is used to prevent infection at the surgical site for 48 hours after the transplant, and sulfamethoxazole / Trimethoprim (SMT) is used for at least a year to prevent opportunist infections occurring subsequent to the transplant. Of the patients with nasal colonization by S.aureus, 12 $(80 \%)$ used SMT immediately after the transplant and 10 $(66.7 \%)$ used cephalosporins.

In Table 2, we present the characteristics of the transplant, along with donor and immunosuppression type.

Table 2 - Transplant characteristics, type of donor and immunosuppression - Sao Paulo, 2011

\begin{tabular}{lccccc}
\hline \multirow{2}{*}{ Characteristics } & \multicolumn{2}{c}{ Staphylococcus aureus } & \multicolumn{2}{c}{ Negative } & \multirow{2}{*}{$\boldsymbol{p}$} \\
\cline { 2 - 4 } & $\mathbf{n}=\mathbf{1 5}$ & $\mathbf{\%}$ & $\mathbf{n = 1 4 5}$ & $\mathbf{\%}$ & \\
\hline Renal donor & & & & & \\
$\quad$ HLA I and II & 8 & 53.3 & 83 & 57.2 & \\
HLA III and deceased donor & 7 & 46.7 & 62 & 42.8 & \\
Immunosuppressant drugs & & & & \\
$\quad$ Mycophenolate mofetil & 4 & 26.7 & 34 & 23.4 & 0.756 \\
$\quad$ Tacrolimus & 7 & 46.7 & 55 & 37.9 & 0.509 \\
\hline
\end{tabular}


Continuation...

\begin{tabular}{|c|c|c|c|c|c|}
\hline \multirow{2}{*}{ Characteristics } & \multicolumn{2}{|c|}{ Staphylococcus aureus } & \multicolumn{2}{|c|}{ Negative } & \multirow[b]{2}{*}{$\mathbf{p}$} \\
\hline & $n=15$ & $\%$ & $n=145$ & $\%$ & \\
\hline Ciclosporin & 8 & 53.3 & 80 & 55.2 & 0.892 \\
\hline Azathioprine & 2 & 66.7 & 98 & 67.6 & 0.999 \\
\hline Prednisone & 14 & 93.3 & 144 & 99.3 & 0.179 \\
\hline
\end{tabular}

There was no statistically significant association between the state of the S.aureus carrier and the characteristics of the renal transplant, donor type or immunosuppressant drugs used.

The prevalence of colonization by S.aureus found in this population was $9.4 \% .14$ (93.3\%) of this group had S.aureus that was sensitive to oxacillin (OSSA) and one (6.7\%) was oxacillin resistant (ORSA). In Table 3 we present the prevalence of S.aureus colonization by time of

renal transplant and immunosuppression protocol.

The analysis of colonization prevalence according to immunosuppressant protocols adopted during Service for patients up to 30 days since transplant (loading dosage), those after between two and six months (adequacy dosage) and between six months and a year (maintenance dosage) show that the isolation rates of the microorganism were $60 \%$, $13.3 \%$ and $26.7 \%$ respectively, with statistical significance $(p<0.05)$ in the prevalence in all cases.

Table 3 - Isolation of nasal S.aureus from renal receptors, in relation to time of transplant and immunosuppressant dosage - Sao Paulo, 2011

\begin{tabular}{|c|c|c|c|c|c|}
\hline \multirow{2}{*}{ Time of transplant and immunosuppressant dosage } & \multicolumn{2}{|c|}{ Staphylococcus aureus } & \multicolumn{2}{|c|}{ Negative } & \multirow{2}{*}{$\mathrm{p}(*)$} \\
\hline & $n=15$ & $\%$ & $n=145$ & $\%$ & \\
\hline Up to 30 days/loading dosage $(n=60)$ & 9 & $60.0^{*}$ & 51 & 35.2 & \\
\hline 60 to 180 days/loading dosage $(n=50)$ & 2 & $13.3^{*}$ & 48 & 33.1 & $<0.05$ \\
\hline 180 days -1 year / maintenance dosage $(n=50)$ & 4 & $26.7^{*}$ & 46 & 31.7 & \\
\hline Total & 15 & 100 & 145 & 100 & \\
\hline
\end{tabular}

\section{DISCUSSION}

The high rates of morbidity and mortality related to S.aureus among patients who have undergone renal transplant highlight the need and importance of defining healthcare strategies to prevent the colonization and transmission of this microorganism in this specific group $^{(12)}$. Between 1995 and 2002, the percentage of dialysis centers in the USA that treated one or more patients with ORSA increased from $40 \%$ to $70 \%$. Between 1997 and 2000, five of every six patients diagnosed with S.aureus and with intermediary resistance to vancomycin had carried out dialysis. In 2005, ORSA infections of the bloodstream were found to occur in 45.2 of every 1,000 dialysis patients ${ }^{(6)}$. In kidney transplant patients, the initial intense immunosuppression associated with the invasive procedures carried out in the period pre and post-transplant increase the risk of infections by microorganisms, with the most common being S.aureus. In patients with ESRD, there is greater exposure to risk factors related to colonization and infection by the agent, both in the substitute therapy period and in the phases before and after the transplant.

A study conducted at the peritoneal dialysis clinic in a university hospital surveyed 98 patients to determine the nasal colonization and the outlet site of the peritoneal catheter for S.aureus. All samples were OSSA and $44 \%$ of patients were considered to suffer from chronic colonization of the microorganism. The relative risk of any infection in chronic carriers, compared to intermittent carriers, was 2.91 times greater (IC 95\%; 2.17 - 3.90), and the relative risk of infection by $S$.aureus was 3.42 times greater (IC 95\%; $2.40-4.88$ ). The persistence of S.aureus colonization was associated with an increase in infection rates. The authors suggested that on-going monitoring was required in order to detect the emergence of new patients infected ${ }^{(16)}$.

A separate prospective study monitored patients colonized by ORSA that had been admitted to five hospital units (medico-surgical clinics, clinical intensive care units ICUs, surgical ICUs, trauma ICUs and semi-intensive units). Nasal samples were collected and the patients were monitored for one year. Of the 758 patients monitored since admission, $3.4 \%$ were colonized by ORSA and $21 \%$ by OSSA. A total of $19 \%$ of patients with ORSA upon admission and $25 \%$ who had become infected after admission developed the infection compared with $1.5 \%$ of patients colonized by OSSA $(p<0.01)$ and $2.0 \%$ not colonized $(p<0.01)$. The authors suggested that monitoring and accompaniment strategies were required for colonized patients in order to reduce the infections caused by ORSA ${ }^{(17)}$.

A multicenter prospective study was carried out at 14 intensive therapy units in France over a six month period and detected the prevalence of nasal carriers of ORSA upon admission at these units. Of 2,347 patients admitted, 162 (6.9\%) were ORSA positive. In patients that had been readmitted, the prevalence of ORSA was $22.2 \%$. In a multivariate analysis, the risk factors associated with nasal carriers of ORSA were: age over 60, prolonged period of hospitalization, history of hospitalization or surgery and presence of open skin lesions. The author suggested that nasal swabs should be collected 
as routine in patients admitted to intensive therapies, in order to identify those who were carriers and to instigate control measures ${ }^{(18)}$.

The prevalence of nasal colonization is as common in renal patients as it is in their family members and in healthcare professionals. An East Asian study evaluated the nasal colonization, infection and transmission rate of Staphylococcus aureus in patients from the dialysis program, along with their family members and health professionals. Of the 1,687 samples collected in a year, in three periods, the colonization rate for ORSA was $2.41 \%$ $(2 / 83)$ in peritoneal dialysis and $2.36 \%(12 / 509)$ in hemodialysis. Of these patients, five (5/14) were infected by ORSA with similar clinical and colonization samples, showing that the colonization preceded the infection ${ }^{(19)}$.

A study carried out in a Brazilian hospital evaluated nasal and palm colonization of 151 nursing professionals that worked in the surgery center, the intensive care unit and in nephrology/hemodialysis. Of the 302 samples collected, $25.8 \%$ were positive for S.aureus. Of the 39 professionals infected, $25.6 \%$ had positive samples on their hands, $48.8 \%$ had positive nasal samples and $25.6 \%$ had both. Of the five positive ORSA samples (3.3\%), all were found in the nasal sample $\mathrm{e}^{(20)}$.

A number of studies have reported on the need for multiple strategies to reduce S.aureus infections. One such study describes the actions adopted that resulted in an $82 \%$ reduction in ORSA infections in two units for patients in critical conditions, which included nasal samples upon admission, release and transferal of patients, precautions regarding contact, and other measures. In the four years after establishing these procedures, there was a decrease in ORSA infections from 1.4 infections per patient/day to $0.27^{(21)}$. Some authors have studied strategies for nasal decolonization and its impact in the reduction of infections in situations where S.aureus became highly prevalent, as well as the benefits and risks of these measures. The CDC and APIC recommendations to avoid the spread of ORSA include nasal decolonization in specific situations, including the use of antibiotics ${ }^{(22-23)}$. These data confirm the importance of studying the prevalence of S.aureus among kidney transplant patients, given that there is little information available on nasal colonization by the agent in this group of patients and in view of the associated risks.

A different study involved a retrospective investigation in the period of a year in order to compare microbial resistance in 207 diabetic patients divided into three groups: those who had undergone a kidney transplant $(n=21)$, hemodialysis $(n=22)$ and other patients $(n=164)$. S.aureus was the second most common agent in the three groups, with a $21 \%$ S55\% and $32 \%$ respectively ${ }^{(24)}$.

A retrospective study analyzed the incidence of peritonitis up to 90 days after the renal transplant. Between 1980 and 1995, 238 transplants were carried out in patients who underwent peritoneal dialysis. Of the 232 cases evaluated, 30 episodes of peritonitis were found. Of these, 10 (33.3\%) were for S.aureus. Seven patients had peritonitis from S.aureus prior to the transplant and this was found to be the principle risk factor in a univariate analysis. The hypothesis presented by the authors was that the patients were nasal carriers of S.aureus ${ }^{(25)}$.

A case study described enterocolitis with ulceration and perforation of the colon on the fifth day after renal transplant in a 46 year-old patient. Cultures from abdominal and pos-mortem material showed that the disease/infection was caused by ORSA ${ }^{(26)}$. This result was presented in a study of 159 patients in which nasal samples were collected from patients who had undergone kidney transplant or who were undertaking dialysis. Nasal colonization of S.aureus was found in $75 \%$ (36/48) of the transplant patients and in $49 \%$ (55/111) of dialysis patients, highlighting the need for prevention and control measures in this group of patients ${ }^{(27)}$.

Knowing the colonization rate of patients would allow for the creation of strategies to avoid the dissemination of microorganisms and the development of resistance to glycopeptides, with the growth of resistant strains. S.aureus can be isolated from other regions of the body, such as the armpits and perineum ${ }^{(5)}$.

One of the limitations of this study is the fact that the collection was carried out just once and only in the nasal region. In addition, it was not possible to carry out a follow-up with patients to determine whether they were intermittent or chronic carriers of S.aureus. At the center where the study was carried out an antimicrobial prophylaxis is administered to $100 \%$ of transplant patients. A nasal collection was not performed prior to the inclusion of the patient in the study, which could have determined if the use of antibiotics that began in the period immediately after transplant surgery could have been a factor in the decolonization of patients who had previously been colonized. Of all the patients for whom samples were collected, 140 (87.5\%) used SMT after the transplant. However, of the 15 patients colonized by S.aureus, nine (60\%) had been using antibiotics for just two days. Is it possible that in the group of patients that had negative results for S.aureus, this antibiotic had a protective effect and in the colonizers the short period of use meant that decolonization had not yet been instigated? Studies are required in order to establish the protective effect of the antibiotic. The use of antibiotics, collected previously, is a theme that deserves further investigation. We believe collection should be increased to other colonization sites, such as the perineal and axillary regions, and that cultures should be gathered prior to transplant.

The statistical analysis showed that indeterminate primary renal illness was significant among patients infected with S.aureus $(p=0.02)$. This finding highlights a study limitation, since in the medical records that were
Prevalence of Staphylococcus aureus colonization in renal transplant patients Lamblet LCR, Barbosa DA 
studied it was not possible to obtain information about specific patients with the illness. Many patients are forwarded to the service with the primary cause being indeterminate renal insufficiency, since there are failures in epidemiological information about the illness. There was a statistically significant association between access time greater than one year in dialysis $(p=0.02)$ and S.aureus nasal colonization. Of the 15 patients colonized, $13(86.7 \%)$ were undergoing hemodialysis by means of an arteriovenous fistula and two (13.3\%) through a central venous catheter. Other studies have shown the relationship between nasal colonization, catheter site and increased risk of infection among patients with ESRD (4$7,16)$. The finding highlights the need to review antisepsis practices and those relating to the manipulation of the arteriovenous fistula. The statistically significant difference $(p<0.05)$ between the prevalence of colonization according to immunosuppression protocols for patients with up to 30 days of transplant (loading dosage), those with between two and six months (adequacy dosage) and more than six months (maintenance dosage) shows and reinforces the need for greater surveillance of the

\section{REFERENCES}

1. Boucher HW, Corey GR. Epidemiology of methicillin-resistant Staphylococcusaureus. Clin Infect Dis. 2008;46 Suppl 5: S344-9.

2. Klevens RM, Morrison MA, Nadle J, Petit S, Gershman K, Ray S, et al. Invasive methicillin-resistant Staphylococcus aureus infections in the United States. JAMA. 2007;298(15):1763-71.

3. Gorwitz RJ, Kruszon-Moran D, McAllister SK, McQuillan G, McDougal LK, Fosheim GE, et al. Changes in the prevalence of nasal colonization with Staphylococcus aureus in the United States, 2001-2004. J Infect Dis. 2008;197(9):1226-34.

4. United State Renal Data System. 2012 Annual Data Report: atlas of chronic kidney disease and end-stage renal disease in the United States. Am J Kidney Dis. 2012;61(1 Suppl 1):e1-e480.

5. Wertheim HF, Melles DC, Vos MC, van Leeuwen W, van Belkum A, Verbrugh $\mathrm{HA}$, et al. The role of nasal carriage in Staphylococcus aureus infections. Lancet Infect Dis. 2005;5(12):751-62.

6. Siegel JD, Rhinehart E, Jackson M, Chiarello L; Healthcare Infection Control Practices Advisory Committee. Management of multidrug-resistant organisms in healthcare settings, 2006 [Internet]. 2006 [cited 2008 Jan 21]. Available from: http://www. cdc.gov/hicpac/pdf/MDRO/MDROGuideline2006.pdf

7. Sesso RCC, Barbosa DA, Leme IL, Sader H, Canziani ME, Manfredi $S$, et al. Staphylococcus aureus prophylaxis in hemodialysis patients using central venous catheter: effect of mupirocin ointment. J Am Soc Nephrol. 1998;9(6):1085-92. state of the nasal carrier in this population of patients. It is probable that this evaluation might determine definitively whether a specific action, intervention or treatment that is applied to the patient with ESRD has had a beneficial or protective effect on the state of the nasal carrier of S.aureus.

\section{CONCLUSION}

The prevalence in the present study showed 15 kidney recipient patients infected with S.aureus (9.4\%) and one of these $(6.7 \%)$ was colonized by ORSA. The risk factors in the study that showed statistical significance in a bivariate analysis were access time prior to transplant $(p=0.029)$ and indeterminate primary renal illness $(p=0.029)$. On the basis of these findings and the detection of this number of patients as nasal carriers and the low incidence of ORSA, we recommend a screening of patients treated at the dialysis center and of renal transplant patients. New studies are necessary to determine strategies to prevent the transmission of microorganisms, principally during the first year of renal transplant.
8. Associação Brasileira de Transplantes de Órgãos. Registro Brasileiro de Transplante. RBT [Internet]. 2010 jan/dez [citado 2011 out. 7]. Disponível em: http://www.abto.org.br/abtov03/Upload/file/RBT/2010/1.pdf

9. Grothe C, Belasco AGS, Bettencourt ARC, Diccini S, Vianna LAC, Pignatari $A$, et al. Lethality of endocarditis due to $S$. aureus among patients on hemodialysis. Nephrol Nurs J. 2009;36(6):613-9, 632.

10. Grothe C, Belasco AGS, Bittencourt ARC, Vianna LAC, Sesso RCC, Barbosa DA. Incidence of bloodstream infection among patients on hemodialysis by central venous catheter. Rev Latino Am Enfermagem. 2010;18(1):73-80.

11. Fram D, Castrucci FM, Taminato M, Godoy-Martinez P, Freitas MC, Belasco AGS, et al. Cross-transmission of vancomycin-resistant Enterococcus in patients undergoing dialysis and kidney transplant. Braz J Med Biol Res. 2010;43(1):115-9.

12. Sousa SR, Galante NZ, Barbosa DA, Pestana JOM. Incidence of infectious complications and their risk factors in the first year after renal transplantation. J Bras Nefrol. 2010;32(1):77-84.

13. Kloos WE, Jorgensen JH. Staphylococci. In: Lennette EH, Balows A, Hausler WJ, Shadomy HJ. Manual of clinical microbiology. 4th ed. Washington: American Society for Microbiology; 1985. p. 143-53.

14. National Committe for Clinical Laboratory Standards. Methods for dilution antimicrobial susceptibility test for bacteria that grow aerobically. Approved standard M7-A5. 5th ed. Wayne (PA): NCCLS; 2000. 
15. Armitage P, Berry, G. Statistical methods in medical research. 3rd ed. Oxford: Blackwell; 1994.

16. Nouwen J, Schouten J, Schneebergen P, Snijders S, Maaskant J, Koolen $\mathrm{M}$, et al. Staphylococcus aureus carriage patterns and the risk of infections associated with continuous peritoneal dialysis. J Clin Microbiol. 2006;44(6):2233-6.

17. Davis KA, Stewart JJ, Crouch HK, Florez CE, Hospenthal DR. Methicillin-resistant Staphylococcus aureus (MRSA) nares colonization at hospital admission and its effect on subsequent MRSA infection. Clin Infect Dis. 2004;39(6):776-82.

18. Lucet JC, Chevret S, Durand-Zaleski I, Chastang C, Régnier B; Multicenter Study Group. Prevalence and risk factors for carriage of methicillin-resistant Staphylococcus aureus at admission to the intensive care unit: results of a multicenter study. Arch Intern Med. 2003;163(2):181-8.

19. Lu PL, Tsai JC, Chiu YW, Chang FY, Chen YW, Hsiao CF, et al. Methicillin-resistant Staphylococcus aureus carriage, infection and transmission in dialysis patients, healthcare workers and their family members. Nephrol Dial Transplant. 2008;23(5):1659-65.

20. Silva ECBF, Samico TM, Cardoso MM, Rabelo MA, Bezerra Neto $\mathrm{AM}$, Melo FL, et al . Colonization by Staphylococcus aureus among the nursing staff of a teaching hospital in Pernambuco. Rev Esc Enferm USP. 2012;46(1):132-7.

21. Richmond I, Bernstein A, Creen C, Cunningham C, Rudy M. Best-practice protocols: reducing harm from MRSA. Nurs Manage. 2007;38(8):22-7.
22. Association for Professionals in Infection Control and Epidemiology. Guide to the elimination of methicillin-resistant Staphylococcus aureus (MRSA) transmission in hospital settings. Chicago: APIC; 2007.

23. Coia JE, Duckworth GJ, Edwards DI, Farrington M, Fry C, Humphreys $\mathrm{H}$, et al.; Joint Working Party of the British Society of Antimicrobial Chemotherapy; Hospital Infection Society; Infection Control Nurses Association. Guidelines for the control and prevention of meticillin-resistant Staphylococcus aureus (MRSA) in healthcare facilities. J Hosp Infect. 2006;63 Suppl 1:S1-44.

24. Fejfarová V, Jirkovská A, Petkov V, Boucek P, Skibová J. Comparison of microbial findings and resistance to antibiotics between transplant patients, patients on hemodialysis, and other patients with the diabetic foot. J Diabetes Complications. 2004;18(2):108-12.

25. Bakir N, Surachno S, Sluiter WJ, Struijk DG. Peritonitis in peritoneal dialysis patients after renal transplantation. Nephrol Dial Transplant. 1998;13(12):3178-83.

26. Nomura T, Tasaki Y, Hirata Y, Emoto A, Yamasaki M, Mimata $\mathrm{H}$, et al. Intestinal perforation after cadaveric renal transplantation. Int J Urol. 2004;11(9):774-7.

27. Giarola LB, Santos RR, Tognim MCB, Borelli SD, Bedendo J. Carriage frequency, phenotypic and genotypic characteristics of Staphylococcus aureus isolated from dialysis and kidney transplant patients at a hospital in northern Paraná. Braz J Microbiol. 2012;43(3):923-30. 